\title{
Sobre François Leuret e sua obra
}

\author{
Marluce Maria de Godoy e Silva
}

Desde a origem da clínica psiquiátrica com Philippe Pinel (1809), o recurso à observação como "orientação consciente e sistemática”" no campo da experiência, tem sido o que permite ao clínico praticar a terapêutica com conhecimento de causa. E não é outra a exortação com a qual François Leuret (1846) inicia suas "Indicações a seguir no tratamento moral da loucura”.

Construída em conformidade com os fatos clínicos, a obra de Leuret (1826-1846) recebeu a influência teórica do tratamento moral da loucura desenvolvido na primeira metade do século XIX. Ancorado nas concepções de Pinel (1809) e Esquirol (1838), Leuret foi um adepto fervoroso dessa abordagem. Entretanto, foi alvo de uma pesada reprovação, por parte de um grande número de teóricos de sua época, devido ao que foi considerado o mal uso feito por ele na abordagem moral das paixões e dos excessos, na medicina da alienação (Morel, 1998).

Atualmente Leuret tem sido lembrado como um dos inventores dos jeux de rôle: ${ }^{2}$ sua opção por este recurso se fez sempre através de peças

1. Cf. Bercherie, 1989. p.31

2. O jeux de rôle é um jogo de associações que tem sua origem nos contos ao redor da lareira. Os espectadores participam do conto imaginando as ações dos personagens. $\mathrm{O}$ contista conduz o jogo levando em conta essas ações na seqüência de seu relato. Assim a história se constrói graças à imaginação do conjunto dos participantes. É, então, um tipo de conto interativo. 
$\begin{array}{lllllll}R & E & V & I & S & T & A\end{array}$

LATINOAMERICANA

DE PSICOPATO LOGIA

F U N D A M E N TA L

ano VIII, n. 3, set/2005

alegres e sua escolha dos atores jamais era feita visando o interesse teatral, pois tinha por objetivo fazer o doente representar um papel que lhe fosse útil em relação ao seu tratamento e à sua cura (ibid.). No prefácio à recente reedição das “Indicações a seguir no tratamento moral da loucura”, Pierre Morel (ibid.) relata que Joseph Wolpe (1915-1977) ${ }^{3}$ não escondia o fato de que Leuret ocupava, em seus escritos, o lugar de um dos precursores da terapia comportamental; linha de tratamento adotada para o desaparecimento do sintoma por meio de intervenções que, à maneira do tratamento moral, propõe uma interrupção de um condicionamento e utiliza em sua técnica as encenações como um dos recursos da terapêutica.

Nos dias de hoje, verifica-se que a vertente psicoterápica neurocognitiva das práticas comportamentais mantém estreitos laços com a concepção psiquiátrica advinda do discurso neurocientífico. O que a psiquiatria neurocognitiva propõe é uma reaproximação com a ortodoxia médica que se dá ao custo de um abandono da clínica e da nosologia psiquiátrica clássica, trazendo consigo o risco de vermos desaparecer os elementos que constituem o saber positivo através do qual essa clínica se sustenta.

Portanto, a lembrança dos preceitos formulados acima por Pinel, e reiterados por Leuret, pela publicação de fragmentos de "Indicações a seguir no tratamento moral da loucura" no presente número da Revista Latinoamericana de Psicopatologia Fundamental, constitui-se na invocação de uma clínica construída por meio da observação do doente e no encontro com ele. É, portanto, um retorno aos fundamentos que instituíram a clínica da alienação mental.

Nascida a partir de uma heterogeneidade, conseqüência da disjunção entre, de um lado, a percepção social da loucura, orientada por uma razão ética e, de outro, a tentativa de integrar a racionalidade médica ao conhecimento discursivo da loucura (Machado, 1981), a clínica da alienação mental guarda ainda hoje, de sua gênese, os resquícios de sua herança moral. Esses resquícios podem ser reconhecidos em diversos momentos desta prática, a exemplo da categoria de "mal respondedor, utilizada para os pacientes que apresentam uma resposta insuficiente diante de uma intervenção farmacológica qualquer instituída, e no

3. Joseph Wolpe (1915-1997), nascido no Sul da África, é mais conhecido pelo seu trabalho de dessensibilização sistemática; uma metodologia proposta para tratar pessoas com extrema ansiedade, advinda de eventos específicos, situações, coisas ou pessoas. Sua abordagem envolve o desenvolvimento de uma hierarquia de situações causadoras de ansiedade, ensinando técnicas de relaxamento e em seguida associando a situação ansiogênica com o relaxamento, começando do básico ou da menor parcela causadora de ansiedade, parte dessa hierarquia.

http://psy1.clarion.edu/jms/wolpe.html /. 


\section{CLÁSSICOSDA \\ PSICOPATOLOGIA}

ano VIII, n. 3, set/ 2005

uso de diagnósticos psiquiátricos pelo senso comum, com a finalidade de achincalhar alguém, como todos nós alguma vez já ouvimos, nas adjetivações de "Histérica”, "Paranóico" etc.

Assim, a conseqüência da redução da distância entre a percepção social e a teoria médica, determinada pela delimitação de um espaço próprio para a contenção da loucura foi, portanto, o resultado de um deslocamento da percepção social para a percepção médica, calcada na moralidade que fundamentava a razão ética, fruto de uma apreensão social da alienação (ibid.).

A relação de forças entre essas duas vertentes trouxe como conseqüência, na segunda metade do século XVIII, uma mudança em relação ao tratamento dado à alienação que propiciou, no século XIX, com Pinel, o surgimento das bases para a psiquiatria moderna (Bercherie, 1989). O que Pinel inicia é a análise sistemática do campo da alienação e a ordenação dos fenômenos que o constituem, que uma vez nomeados de maneira precisa viriam permitir a passagem do visível para o enunciável, apoiado na concepção dos ideólogos e no aforismo de Condillac. ${ }^{4}$ A doutrina de Pinel sobre a alienação advém de uma teoria "materialista psicofisiológica” (ibid., p. 34), na qual a loucura era a expressão do desarranjo das relações entre a parte física e o moral; as paixões intensas e os excessos de todos os tipos que, atuando no organismo considerado um todo funcional, perturbava-o, levando-o à desorganização cerebral (ibid.).

O tratamento moral, avalizado por estas idéias foi assim preconizado por Pinel: o espírito perturbado podia ser reconduzido à razão desde que retirado do ambiente que havia feito despontar, ou mesmo gerado a doença, e submetido a um tipo de relação autoritária, mistura entre doçura e firmeza, persuasão e “educação médica” (ibid., p.48).

Considerado “o mais fiel e ortodoxo dos discípulos de Pinel”, segundo Bercherie (ibid., p. 48), Jean-Etienne Dominique Esquirol (1838) influenciou diretamente o empreendimento teórico-clínico construído por Leuret.

Ao acompanharmos os dados biográficos deste alienista nascido em 30 de dezembro de 1797, em Nancy, damo-nos conta de que ele não conheceu facilidades no início de sua vida. Em 1816 mudou-se, com o consentimento do pai, para Paris. Obrigado a suprir seu sustento, do qual o pai se desobriga em 1817, Leuret se alista na Légion de la Meurthe em Saint-Denis e passa a freqüentar com assiduidade, na Salpêtrière, as lições de Esquirol (Morel, 1998).

4. “A ciência não é mais do que uma língua bem-feita”; aforismo utilizado por Condilac para expressar a necessidade de "uma língua que nomeasse o real e não os ídolos que faziam dela um instrumento suspeito do conhecimento”. In: Bercherie, Paul. Os fundamentos da clínica: história e estrutura do saber psiquiátrico, p. 32. 


\section{$\begin{array}{lllllll}R & E & V & I & S & T & A\end{array}$ \\ LATINOAMERICANA \\ DE PSICOPATO LOGIA \\ F U N D A M E T A L \\ ano VIII, n. 3, set/2005}

A particularidade da construção do trabalho de Esquirol estava nas descrições clínicas que lhe permitiram levar adiante a análise e a distinção entre as síndromes psicopatológicas, progredindo na concepção nosológica em relação àquela proposta por Pinel. No período compreendido entre 1820 e 1850, seu ensinamento e sua prática obtiveram a concordância dos teóricos da época, o que atraiu para junto dele um número expressivo de adeptos, entre os quais encontrava-se Leuret (Bercherie, 1898).

Naquela época, duas questões fundamentais dividiram e apaixonaram os discípulos de Esquirol (1838). Uma delas diz respeito à teoria das alucinações; a outra tem relação com a rejeição de Pinel e de Esquirol às teorias que explicavam a loucura por meio de uma lesão material do cérebro.

No que concerne à teoria das alucinações, a partir de Esquirol ${ }^{5}$ (1838, apud Lanteri-Laura, 1991, p. 33) duas correntes se estabeleceram em oposição. Leuret, considerando os dados da experiência, concebeu o fenômeno alucinatório sublinhando o caráter sensível, priorizado por Louis Francisque Lélut ${ }^{6}$ representante exponencial da primeira corrente, e insistiu no modelo de dissociação mental que aparecia na definição de Jacques-Joseph Moreau de Tours $^{7}$ (1845), que pertencia à segunda corrente que podia legitimamente reivindicar a paternidade de Esquirol (Bercherie, 1989).

Leuret antecipa, naquele tempo, a teoria mista ou psicossensorial que seria desenvolvida ulteriormente na proposta de J. Baillager (ibid.). A este respeito, Paul Bercherie dirá no comentário sobre a descendência de Esquirol: "Outros, mais inspirados, tentaram penetrar na estrutura psicopatológica dos distúrbios mentais: podemos citar particularmente o notável livro de Leuret, Fragments psychologiques sur la folie (1834), cujas observações surpreendentes seriam retomadas por toda parte" (ibid., p. 33).

A outra questão que dividiu os alunos de Esquirol referiu-se à controvérsia que se deu entre as causas funcionais para as alterações observadas na alienação mental, hipótese de Pinel e de Esquirol, que colocava a medicina mental em

5. "Un homme qui a la conviction intime d'une sensation actuellement perçue alors que nul objet exterieur propre à exciter cette sensation n'est à portée de ses sens, est dans un état d'hallucination: c'est visionnaire”. Esquirol, E. D. “Des hallucinations”. In: Des maladies mentales considérées sous le rapport médical, hygiénique et médico-legal. Paris: J.B. Baillére, 1838, p. 80, apud Lanteri Laura, G. Les hallucinations, p. 33.

6. Louis Francisque Lélut definiu a alucinação como uma transformação das idéias e dos sentimentos em sensações citado em Bercherie, P., Os fundamentos da clínica: história e estrutura do saber psiquiátrico, p. 65.

7. Moreau de Tours, J. Du Haschich et de l’Aliénation Mentale (1845), apud Lanteri Laura, G., Les hallucinations. 


\section{CLÁSSICOSDA \\ PSICOPATOLOGIA}

ano VIII, n. 3, set/ 2005

desigualdade com a ortodoxia da medicina científica tradicional e com as concepções anatomopatológicas prevalentes em seu tempo. A uma corrente anatomista opôs-se outra, funcionalista, que reafirmava as posições de Pinel e Esquirol, dentre eles Leuret, embora este último mantivesse, como outros de sua época, durante um longo tempo de sua vida, a preocupação e interesse em relação à anatomia (ibid.).

Neste contexto, foi Antoine-Athanase Royer-Collard, ${ }^{8}$ médico chefe no hospital em Charenton, quem proporcionou a Leuret - que em 1822 havia sido declarado inapto para a ação militar devido a uma constituição frágil - um emprego como interno, assegurando-lhe a partir daquele momento a moradia e a alimentação necessárias para o início de sua caminhada em direção ao futuro (Morel, 1998).

E Leuret não perdeu tempo. Passou a freqüentar a École Vétérinaire e ali se dedicou apaixonadamente aos trabalhos de anatomia comparada e fisiologia; defendeu sua tese de doutoramento e iniciou sua carreira em Nancy, retornando pouco tempo depois, em 1828, a Paris (ibid.).

No ano de seu retorno, morre Etienne Georget, "homem notavelmente brilhante (...) e que Esquirol tinha em grande estima” (Bercherie, 1989, p. 59) e a Leuret foi confiada a tarefa de substituí-lo na Casa de Saúde de Ivry, assim como nas funções de redator chefe dos Annales d'Hygiéne Publique et de Médicine légale criadas pouco depois que ele assumiu o cargo de Georget (Morel, 1998).

Ainda nesse ano - 1828 - as discussões sobre o desenvolvimento da criminologia colocavam em questão a responsabilidade penal dos criminosos cujos crimes parecem “imotivados”. Sobre isto poderíamos dizer que essas preocupações continuam sendo as nossas, na contemporaneidade. À medida que a fragmentação clínica se espalha, a passagem ao ato se torna mais enigmática, como nos afiança a mídia por meio dos diversos debates atuais suscitados em torno desse tema. Naquela época, a discussão criminalística levou Leuret a fazer dos Annales d'Hygiéne Publique et de Médicine légale uma tribuna para defender estas novas idéias sobre o papel dos médicos peritos na avaliação da irresponsabilidade penal dos alienados (ibid.).

Além de sua significativa contribuição teórico-clínica e seu envolvimento com a medicina legal, Leuret, exerceu um papel expressivo na denúncia às

8. Athanase Royer-Collard foi o primeiro representante da Escola Espiritual Eclética e salientou "a importância de uma função de controle, seleção e síntese: a atenção voluntária, manifestação da ação do eu sobre os automatismos psicológicos”. É a partir da concepção psicológica advinda dessa escola que Esquirol tomou apoio para defender e salientar o desequilíbrio entre as faculdades superiores e a atenção, como a base para a explicação da diversidade dos distúrbios mentais. In: Bercherie, P. Os fundamentos da clínica: história e estrutura do saber psiquiátrico. 
$\begin{array}{lllllll}R & E & V & I & S & T & A\end{array}$

políticas públicas de combate às endemias, desempenhou com vigor seu trabalho em saúde pública na luta contra as epidemias, e também se dedicou, ao longo de sua vida, a atender os menos favorecidos pela sorte (ibid.). Cabe ainda ressaltar que a diversidade de suas atividades não o deixou menos interessado em relação aos grandes debates de sua época, notadamente as pesquisas em anatomia. Em 1839 explicita suas preocupações com a publicação do primeiro tomo de sua Anatomie comparée du système nerveux dans ses rapports avec l'intelligence. O segundo tomo só será publicado em 1857, após a sua morte (ibid.).

Entretanto, por mais rigorosas que tenham sido as pesquisas de Leuret, elas não lhe permitiram extrair as relações entre a configuração cerebral e as funções instintivas, intelectuais e morais, como ele mesmo reconheceu:

Mesmo se as faculdades não se manifestarem jamais sem o intermédio do sistema nervoso do qual elas são consideradas um produto, uma emanação, (...) a loucura não é como uma doença comum, caracterizada por sintomas físicos, e as causas que a produzem, algumas vezes apreciáveis aos sentidos, pertencem a uma ordem de fenômenos completamente alheios às leis gerais da matéria. (Leuret, 1834, apud Morel, 1998, p. VII)

Esta constatação, que relança Leuret em busca de uma causalidade para a doença mental, foi a sua justificativa e escolha para o tratamento moral. De 1834 a 1845 ele consagrou a este tema oito publicações, desde os Fragments psychologiques sur la folie até as Indications à suivre dans le traitement moral de la folie (Morel, 1998).

Malvisto pela comunidade de alienistas de sua época, a despeito de seus feitos, em sua obra de 1834 - Fragments psychologiques - Leuret nos apresenta a justificativa para o fato de que ele seria lembrando pela mesma razão que o condenou: a prescrição orientada para os doentes no tratamento moral: "Não empregais as consolações, pois elas são inúteis (...). Muito sangue frio e quando se tornar necessário, a severidade (...). Uma única corda vibra ainda neles, aquela da dor, tenhais bastante coragem para tocá-la” (Leuret, 1834, apud Morel, 1998, p. IX).

Esse tratamento pode ser visto pelo resumo das sessões de hidroterapia, feito por Morel (1998). Consistem elas em lançar, sobre os doentes estendidos ao sol, cinco, dez, vinte baldes de água, a seis ou oito graus, ou pelas duchas de dois a três segundos, tombadas de uma altura de dois metros, por um registro de dois centímetros de diâmetro, repetidamente, até que o paciente confesse sua loucura e prometa a ela renunciar (Morel, 1998).

Polêmico, Leuret criou uma escola para os seus pacientes que não sabiam ler e nem escrever; organizou e animou sessões de leitura de grupo para eles e introduziu no serviço do refeitório em Bicêtre uma disciplina terapêutica, 


\section{CLÁSSICOSDA \\ PSICOPATOLOGIA}

ano VIII, n. 3, set/ 2005

reformulação esta que pode se inscrever em uma perspectiva de ressocialização dos doentes e consistia no fato de que durante as refeições a presença dos enfermeiros era proibida, as porções de alimentos não podiam ser preparadas para cada um antecipadamente, e foi proscrito qualquer outro procedimento que pressupusesse a lembrança de que os internos encontravam-se em um hospital, assim como qualquer ação que evocasse um ato autoritário: “Cada chefe de mesa deve saber o nome de seus comensais, cuidar para que cada um deles seja bem servido, e tratá-los como se eles (os pacientes) tivessem sido convidados a almoçar em sua companhia” (Leuret, 1840, apud Morel, 1998, p. XVI).

O texto "Indications à suivre dans le traitement moral de la folie", lido em 2 de dezembro de 1945 na Academie Royale de Médicine e publicado pela primeira vez em 1846, é sua última contribuição: “... trata-se da última defesa e ilustração de seus métodos” (Morel, 1998, p. VII). Celibatário, a partir de 1847 sua saúde declina, e em 1851 morre em Paris, François Leuret.

Publicamos nas páginas seguintes a introdução dessa obra, o que permitirá ao leitor familiarizar-se com o pensamento do autor, e dentre as dez indicações clínicas para o tratamento moral por ele descritas, a primeira e a segunda observação, indicativas da distinção feita por Leuret (1846) entre uma sintomatologia determinada por causas somente orgânicas e as de causalidade psíquica para as quais ele justifica o emprego dos meios morais no tratamento.

\section{Referências}

Bercherie, Paul. Os fundamentos da clínica: história e estrutura do saber psiquiátrico. Rio de Janeiro: Jorge Zahar, 1989.

Lanteri-Laura, G. Les hallucinations. Masson: Paris, 1991.

Leuret, François. Indications à suivre dans le tratement moral de la folie. Paris: L’Harmattan, 1998 (Collection Psychanalyse et Civilisations, Série Trouvailles et Retrouvailles, dirigée par Jacques Chazaud).

Machado, Roberto. Uma arqueologia da percepção. In: Ciência e saber - a trajetória da arqueologia de Michel Foucault. Rio de Janeiro: Graal, 1981.

Morel, P. Préface. In: Indications à suivre dans le tratement moral de la folie. Paris: L’Hartmattan, 1998. (Collection Psychanalyse et Civilisations, Série trouvailles et Re1989 trouvailles, dirigée par Jacques Chazaud). 